The Encyclopedia of

\title{
APPLIED ANIMAI
} BEHAVIOUR \&? WELFARE

Edited by Daniel S. Mills, Jeremy N. MarchantForde, Paul D. McGreevy, David B. Morton, Christine J. Nicol, Clive J. C. Phillips, Peter Sandøe $\mathscr{E}$ Ronald R. Swaisgood

Welfare research has established a range of scientific indicators of stress, welfare and suffering in animals that can be applied to all aspects of improving their wellare through good housing and

mablic. Under a team of expert subject editors led by Professor Daniel Mills, the UK's first specialist in veternaty bed a wealth of fully cross-referenced entries ranging from concise definitions to detaite (a) detailed described in domestic, exotic, companion, laboratory, zoo and wild animals, including human animal interactions, animal rights and stereotypic behaviours. and improvement of animals' behaviour without compromising welfare. It will be an essential resource for practising veterinarians, researchers and students in zoology and ethology, and to al

Related titles

Improving Animal Welfare: a Practical Approach
Edtited by . Grandin 2009336 pages ISBN 978184593541 ? The Ethology of Domestic Animals, 2nd Edifition an Introductory Text

Edited by P. Jensen

Principles and Applic

20.PB Price 336 pages ISBN 9781845933982

Domestic Animal Behaviour and Welfare, 4th Edition

Domestic Animal Behaviour and We
D.M. Broom and A.F. Fraser
2007 400 pages ISBN 9781845932879

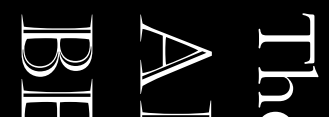

T을

$\stackrel{2}{2}$

룽

풍

$\underline{\nabla}+$

坖》

$\infty Z$

$\&$

$z \sum$

필

F

T

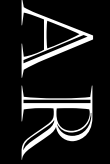

H

(a) $\left.\cos ^{3}\right)$

Mills

Marchant-Forde

McGreevy

Morton

Nicol

Phillips

Sandøe

(b)
The Encyclopedia of APPLIED ANIMAL BEHAVIOUR छु WELFARE

\section{Edited by}

Daniel S. Mills

Jeremy N. Marchant-Forde, Paul D. McGreevy,

David B. Morton, Christine J. Nicol,

Clive J. C. Phillips, Peter Sandøe $\mathcal{E}$ Ronald R. Swaisgood 